\title{
WORLD ORGANISATION OF SYSTEMS AND CYBERNETICS NINTH ICCS '93-NINTH INTERNATIONAL CONGRESS OF CYBERNETICS AND SYSTEMS
}

The Ninth International Congress of Cybernetics and Systems, the triennial congress of the World Organisation of Cybernetics and Systems, will be held at New Delhi, India from Tuesday January 18 through Sunday January 23, 1993. It is being organized jointly by the Society of Management Science and Applied Cybernetics (SOMAC) and the Tata Consultancy Services (TCS). For the first time the Congress of WOSC is being held in an Asian country.

Topics

Various topics will be covered in the following clusters each of which may have multiple sessions.

Clusters

1. Methodological Problems in Systems and Cybernetics (including theory of Fuzzy Sets)

2. Systems Engineering

3. Cybernetics and Systems in Emerging Problems of Development, and Problems of Third World Countries

4. Robotics and Automation

5. Systems Practice

6. Artificial Intelligence and Applications

7. Medical and Bio-cybernetics (including Neuro-cybernetics)

8. Cybernetics in Economics, Social and Behavioural Sciences, Management

9. Computer Communications

10. Others

11. Keynote Addresses

There is a tentative programme of allocating one day (Friday January 21, 1993) exclusively for keynote addresses to be delivered by 8 or 9 eminent scientists.

Submission of Paper: Acceptance of contributed papers will be determined on the basis of final drafts. Papers should not exceed 500 words approximately 6 to 7 single space in A4 pages with maximum 50 lines in each paper) in English. The printed paper must carry the title, author's names, affiliation, and the cluster in which the paper is intended to be presented.

Deadline for submission: June 30, 1992.

Final Papers: Authors will be notified about their acceptance not later than September 30, 1992.

\section{Congress Fees:}

(a) Participants Outside Indian Subcontinent:

$\$ 200$ US if paid before July 31, 1992

$\$ 250$ US if paid later.

(Cheques should be paid in favour of "WOSC" at the office of WOSC, 5 Margate Road, St. Annes-on-Sea, FY8 3EG, Lancs, England, UK).

(b) Participants from Indian Subcontinent:

(India, Pakistan, Bangladesh, Sri Lanka, Nepal, Bhutan)

Rs. 2,000 (Indian) if paid before July 31, 1992

Rs. 2,500 (Indian) if paid later.

(Cheques should be paid in favour of "Society of Management Science and Applied Cybernetics-Congress" and sent to the Secretary, Society of Management Science and Applied Cybernetics, CSIR Complex, New Delhi 110012, India).

\section{ENQUIRIES TO:}

A. GHOSAL Secretary, SOMAC CSIR Complex New Delhi-110012, India Ph: 91-(11)-573-2193 TLX: $31-61-635$ TBC-IN FAX: 91-(11)-34 3703
P. N. MURTHY

Tata Consultancy Services 3rd floor, Shakar Bhavan

Fateh Maidan Road Hyderabad 500004 , India Ph: 91-(842) 23-1246 TLX: 0425-6645 TCSH-IN 